\title{
Capturing echocardiographic allograft valve function over time after allograft aortic valve or root replacement
}

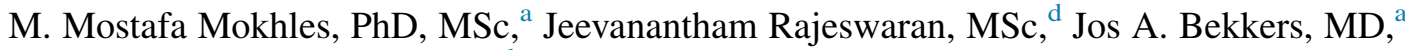 \\ Gerard J. J. M. Borsboom, MSc, ${ }^{b}$ Jolien W. Roos-Hesselink, MD, PhD, ${ }^{c}$ Ewout W. Steyerberg, PhD, ${ }^{b}$ \\ Ad J. J. C. Bogers, MD, PhD, ${ }^{a}$ Johanna J. M. Takkenberg, MD, PhD, ${ }^{a}$ and Eugene H. Blackstone, MD $^{\mathrm{d}, \mathrm{e}}$
}

Objective: This study describes echocardiographic allograft valve function over time in a cohort of patients who were prospectively followed after allograft aortic valve or root replacement, illustrating the use of longitudinal data analysis for assessing valve function over time.

Methods: Serial, standardized echocardiographic measurements of aortic regurgitation, aortic gradient, annulus diameter, left ventricular outflow tract diameter, and aortic diameter in 301 hospital survivors (mean age, 46 years; range, $16-83$ years) after allograft aortic valve $(\mathrm{N}=77)$ or $\operatorname{root}(\mathrm{N}=224)$ replacement were analyzed using nonlinear longitudinal models.

Results: Aortic regurgitation increased over time. At 15 years, $41 \%$ of patients had at least moderate aortic regurgitation. Younger patient age and subcoronary implantation technique were associated with increased aortic regurgitation. Aortic gradient increased over time (from $9.4 \mathrm{~mm} \mathrm{Hg}$ at 6 months to $21.3 \mathrm{~mm} \mathrm{Hg}$ at 15 years); both initial and increase in aortic gradient were greater in younger patients and after subcoronary implantation technique. Annulus diameter slightly increased (from $21.9 \mathrm{~mm}$ at 6 months to $22.4 \mathrm{~mm}$ at 15 years), whereas aortic diameter slightly decreased over time (from $34.3 \mathrm{~mm}$ at 6 months to $32.7 \mathrm{~mm}$ at $15 \mathrm{years}$ ). Left ventricular outflow tract diameter remained constant at $22 \mathrm{~mm}$. Younger patients in the subcoronary implantation group had a larger annulus diameter.

Conclusions: Both aortic regurgitation and stenosis increase over time after allograft aortic valve or root replacement. Younger patient age and use of the subcoronary implantation technique are associated with increased regurgitation and stenosis. The use of nonlinear longitudinal models allows for an insightful analysis of allograft valve function over time. (J Thorac Cardiovasc Surg 2014;148:1921-8)

See related commentary on pages 1929-30.

\section{Supplemental material is available online.}

Allografts have been used for the replacement of the diseased aortic valve for more than 5 decades. ${ }^{1}$ Although allografts were initially thought to be superior to xenografts,

\footnotetext{
From the Departments of Cardiothoracic Surgery, ${ }^{\mathrm{a}}$ Public Health, ${ }^{\mathrm{b}}$ and Cardiology, ${ }^{\mathrm{c}}$ Erasmus University Medical Center, Rotterdam, The Netherlands; and Departments of Quantitative Health Sciences ${ }^{\mathrm{d}}$ and Thoracic and Cardiovascular Surgery, ${ }^{\mathrm{e}}$ Cleveland Clinic, Cleveland, Ohio.

Dr Mokhles is funded by a Mosaic grant of the Netherlands Organisation for Scientific Research (NWO 017.006.058).

Disclosures: Authors have nothing to disclose with regard to commercial support.

Read at the American Heart Association's Scientific Sessions, Los Angeles, Califor-

nia, November 3-7, 2012.

Received for publication Feb 19, 2014; revisions received April 2, 2014; accepted for publication April 11, 2014; available ahead of print June 27, 2014.

Address for reprints: M. Mostafa Mokhles, $\mathrm{PhD}$, MSc, Department of Cardiothoracic Surgery, Room Bd 575, Erasmus University Medical Center, PO Box 2040, 3000 CA Rotterdam, The Netherlands (E-mail: m.mokhles@erasmusmc.nl). $0022-5223 / \$ 36.00$

Copyright (c) 2014 by The American Association for Thoracic Surgery http://dx.doi.org/10.1016/j.jtcvs.2014.04.023
}

today there is increasing evidence that allograft durability is comparable to other biological valve substitutes. ${ }^{2,3}$ Currently, their application is mainly in patients with complex cardiac and aortic root pathology in the setting of an active endocarditis.

The assessment of allograft valve performance over time is difficult. Echocardiographic measurements obtained over time after allograft implantation are usually dichotomized by using time-to-event methods and are reported as, for example, freedom from aortic regurgitation (AR) grade $1+$ or $3+$ at a certain follow-up time. ${ }^{4,5}$ Dichotomization of longitudinal data is often inappropriate because it leads to loss of information and incorrect statistical inferences. The 2008 guidelines for reporting mortality and morbidity after cardiac valvular interventions ${ }^{6}$ propose the use of longitudinal data analysis for series of assessments, such as repeated echocardiographic measurements of valve function to estimate its average temporal pattern and variability in a group of patients. Repeated measurement data have several important characteristics that are taken into account by longitudinal analyses methods but that are not taken into account by time-to-event methods.

The aim of this study is to describe echocardiographic allograft valve function over time in a prospective cohort 


\section{Abbreviations and Acronyms \\ $\mathrm{AR}=$ aortic regurgitation \\ LVOT $=$ left ventricular outflow tract}

of patients who underwent allograft aortic valve or root replacement. This will be done by using and illustrating the use of advanced longitudinal data analysis techniques.

\section{METHODS}

\section{Patients}

Between April 1987 and September 2010, a total of 347 patients underwent 356 aortic valve or root replacements with an allograft at the Erasmus University Medical Center, Rotterdam, The Netherlands (Table 1). After these 356 procedures, 301 hospital survivors had 1 or more standardized echocardiographic examinations. The small number of patients with repeat operations $(n=9)$ were considered as independent patients because the primary focus of this study was allograft valve function over time. Approval from the institutional review board (No. EMC00-813) was obtained for this prospective follow-up study, and all patients provided informed consent. The clinical outcome of the total cohort has been reported. ${ }^{3}$

\section{Surgical Procedures}

Surgical procedures were performed through a median sternotomy on cardiopulmonary bypass with moderate hypothermia (Table 2). Crystalloid cardioplegia and topical cooling were used for myocardial protection. Deep hypothermia and circulatory arrest were used in 32 patients with ascending aorta or arch pathology. Early in our experience, the subcoronary technique was used; since 1998, root replacement has become the technique of choice. Of the 356 procedures, subcoronary allograft implantation was performed in 94 patients $^{7}$ and root replacement was performed as a freestanding root with reimplantation of the coronary arteries in 262 patients. From these patients, 1 or more standardized echocardiographic examinations were available for 77 patients who underwent the subcoronary allograft implantation technique and 224 patients who underwent the root replacement technique.

\section{Echocardiographic Follow-up}

Serial, standardized echocardiography has been performed at Erasmus University Medical Center in all patients aged 16 years or more who received human tissue valves since 1987. Postoperative echocardiographic examinations were scheduled at 6 months, at 1 year, and thereafter once every 2 years. ${ }^{8}$ A detailed description of the echocardiographic followup can be found in the Online Methods Supplement.

\section{Statistical Analyses}

All the analyses were performed using SAS9.1 (SAS Institute Inc, Cary, NC), and some plots were created using S-Plus6.2 statistical software (Insightful Corp, Lucent Technologies Inc, Palo Alto, Calif).

\section{Analyses of clinical data}

Presentation. Continuous variables are summarized as mean \pm standard deviation, and comparison was done using the unpaired $t$ test unless the data were not normally distributed (Kolmogorov-Smirnov test); in these instances, we used the Mann-Whitney $U$ test for comparison. Categoric data are presented as proportions, and comparison was done using the chi-square test or Fisher exact test where appropriate. All tests were 2 -sided, with an alpha level of 0.05 .

Survival analyses. Overall nonparametric survival estimates were obtained by the method of Kaplan-Meier. A parametric method was used to resolve the number of phases of instantaneous risk of death (hazard function) and to estimate the shaping parameters. ${ }^{9}$ To identify risk factors for death, multivariable analyses were performed in the multiphase hazard function domain.

In the multivariable analysis, factors modulating both hazard phases were considered simultaneously. Early risk factors are those found to increase the area beneath the early decreasing hazard phase, and late risk factors are those that increase the level of underlying increasing hazard. Within each hazard phase, we assume proportional hazards, but because the 2 hazard phases are operative across all time, this produces overall a nonproportional hazard model. Such a model is particularly appropriate for strongly time-varying hazard, as is evident for these events.

Reoperation analyses. Reoperation and multivariable analyses of patients who underwent reoperation were performed in a similar method used to study survival.

\section{Analyses of echocardiographic data}

Categoric echocardiographic measurement. To assess the temporal trend of likelihood of AR grades over time after surgery, follow-up transthoracic echocardiograms were analyzed longitudinally for percentages of patients in each AR grade across time. Because there is no practical method for continuous heart valve function assessment, a nonlinear cumulative logit mixed model ${ }^{10,11}$ was used to resolve a number of time phases on cumulative odds domain to form a temporal decomposition model and to estimate the shaping parameters at each phase. A longitudinal cumulative logistic mixed model ${ }^{12,13}$ for repeated measurements (SAS PROC NLMIXED; SAS Institute Inc) was used to implement the temporal decomposition model and to estimate the patient-specific probabilities for being in each AR grade. These patient-specific estimates were then averaged to obtain the percentages of patients (prevalence) in each grade. These methods were applied because they simultaneously solve multiple challenges of continuously collected echocardiographic data (eg, repeated measurements for each patient, variable time of recording, censoring by death). Continuous echocardiographic measurement. To assess the temporal trend of aortic valve gradient, annulus diameter, aortic diameter, and left ventricular outflow tract (LVOT) diameter over time after surgery, follow-up transthoracic echocardiographic measurements were analyzed longitudinally for change in mean response across time. ${ }^{14}$ A nonlinear longitudinal mixed model regression ${ }^{12,13}$ (SAS PROC NLMIXED; SAS Institute Inc) was used to analyze these continuous repeated measurements.

\section{RESULTS \\ Perioperative Details}

Table 2 shows the perioperative details. There were 4 patients (all root replacements) who required coronary artery bypass grafting because of problems related to the reinsertion of the coronary arteries. The detailed causes were as follows: In 1 patient the left coronary artery button was too small, causing coronary ostium stenosis; 1 patient had annular calcifications extending up to the right coronary ostium that was thin-layered and ruptured after reimplantation; 1 patient had right ventricular dysfunction due to kinking of the reimplanted right coronary artery; and in 1 patient, the attending surgeon made the decision to perform coronary artery bypass grafting on the basis of his observations of suboptimal coronary flow causing malperfusion of both the right and left coronary arteries. Hospital mortality was $5.9 \%$ (21/356 surgical procedures).

\section{Clinical Follow-up}

During follow-up, another 79 patients died (2.1\%/patient year): Deaths were not valve related and were noncardiac in 
TABLE 1. Baseline characteristics of patients used for clinical follow-up (total cohort) and echocardiographic follow-up (echocardiography cohort)

\begin{tabular}{|c|c|c|c|c|c|c|c|}
\hline \multirow[b]{2}{*}{ Characteristic } & \multicolumn{2}{|c|}{$\begin{array}{c}\text { Total cohort } \\
(n=356)\end{array}$} & \multicolumn{2}{|c|}{$\begin{array}{c}\text { Echocardiography } \\
\text { cohort }(n=301)\end{array}$} & \multirow{2}{*}{ 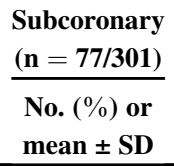 } & \multirow{2}{*}{$\begin{array}{l}\text { Root replacement } \\
(n=224 / 301) \\
\text { No. }(\%) \text { or } \\
\text { mean } \pm \text { SD }\end{array}$} & \multirow{2}{*}{$\begin{array}{c}\begin{array}{c}\text { Subcoronary vs } \\
\text { root replacement }\end{array} \\
P \text { value } \\
\end{array}$} \\
\hline & $\mathbf{n}(\%)^{*}$ & $\begin{array}{l}\text { No. }(\%) \text { or } \\
\text { mean } \pm \text { SD }\end{array}$ & n $(\%)^{*}$ & $\begin{array}{l}\text { No. }(\%) \text { or } \\
\text { mean } \pm \text { SD }\end{array}$ & & & \\
\hline \multicolumn{8}{|l|}{ Demography } \\
\hline Age (y) & $356(100)$ & $44.4 \pm 16.4$ & $301(100)$ & $45.6 \pm 14.5$ & $46 \pm 14.1$ & $45.4 \pm 14.7$ & .9 \\
\hline Gender & $356(100)$ & & $301(100)$ & & & & .88 \\
\hline Male & & $251(71)$ & & $217(72)$ & $55(71)$ & $162(72)$ & \\
\hline Female & & $105(29)$ & & $84(28)$ & $22(29)$ & $62(28)$ & \\
\hline $\operatorname{BSA}\left(\mathrm{m}^{2}\right)$ & $356(100)$ & $1.89 \pm 0.26$ & $301(100)$ & $1.93 \pm 0.2$ & $1.91 \pm 0.19$ & $1.94 \pm 0.2$ & .5 \\
\hline Creatinine $(\mu \mathrm{mol} / \mathrm{L})$ & 354 (99) & $103 \pm 85.2$ & $300(100)$ & $97.8 \pm 62.4$ & $109 \pm 101$ & $93.8 \pm 41.5$ & .033 \\
\hline \multicolumn{8}{|l|}{ Symptoms } \\
\hline NYHA functional class & $355(100)$ & & $300(100)$ & & & & $<.001$ \\
\hline I & & $92(26)$ & & $83(28)$ & $11(14)$ & $72(32)$ & \\
\hline II & & $95(27)$ & & $81(27)$ & $21(27)$ & $60(27)$ & \\
\hline III & & $105(30)$ & & $89(30)$ & $38(49)$ & $51(23)$ & \\
\hline IV & & $63(18)$ & & $47(16)$ & $7(9.1)$ & $40(18)$ & \\
\hline Timing of surgery & 354 (99) & & 299 (99) & & & & .007 \\
\hline Surgery within $24 \mathrm{~h}$ & & $39(11)$ & & $30(10)$ & $2(2.6)$ & $28(13)$ & \\
\hline $\begin{array}{l}\text { Surgery within the same } \\
\text { hospitalization }\end{array}$ & & $101(29)$ & & $84(28)$ & $17(22)$ & $67(30)$ & \\
\hline Elective surgery & & $214(60)$ & & $185(62)$ & $58(75)$ & $127(57)$ & \\
\hline Ventilation support & $356(100)$ & $21(5.9)$ & $301(100)$ & $14(4.7)$ & $0(0)$ & $14(6.3)$ & .025 \\
\hline Aortic valve & $355(100)$ & & $289(96)$ & & & & .092 \\
\hline Pure aortic stenosis & & $68(19.2)$ & & $59(20)$ & $21(27)$ & $38(17)$ & \\
\hline Pure AR & & $206(58.0)$ & & $175(58)$ & $43(56)$ & $132(59)$ & \\
\hline Mixed AR/stenosis & & $65(18.3)$ & & $55(18)$ & $13(17)$ & $42(19)$ & \\
\hline \multicolumn{8}{|l|}{ Noncardiac comorbidity } \\
\hline DM & $356(100)$ & $12(3.4)$ & $301(100)$ & $8(2.7)$ & $3(3.9)$ & $5(2.2)$ & .43 \\
\hline Hypertension & $356(100)$ & $51(14)$ & $301(100)$ & $40(13)$ & $10(13)$ & $30(13)$ & .93 \\
\hline Renal disease & 353 (99) & $12(3.4)$ & 298 (99) & $5(1.7)$ & $3(3.9)$ & $2(0.9)$ & .078 \\
\hline CVA & $356(100)$ & $19(5.3)$ & $301(100)$ & $16(5.3)$ & $7(9.1)$ & $9(4)$ & .087 \\
\hline Rhythm & 354 (99) & & $300(100)$ & & & & .4 \\
\hline Sinus rhythm & & $326(92)$ & & $284(95)$ & $71(92)$ & $213(96)$ & \\
\hline Atrial fibrillation & & $11(3.1)$ & & $6(2)$ & $2(2.6)$ & $4(1.8)$ & \\
\hline Heart block & & $9(2.5)$ & & $7(2.3)$ & $2(2.6)$ & $5(2.2)$ & \\
\hline Other rhythm & & $8(2.3)$ & & $3(1)$ & $2(2.6)$ & $1(0.45)$ & \\
\hline Left ventricular function & $348(98)$ & & $298(99)$ & & & & .54 \\
\hline Good & & $260(75)$ & & $222(74)$ & $59(77)$ & $163(74)$ & \\
\hline Impaired & & $64(18)$ & & $55(18)$ & $14(18)$ & $41(19)$ & \\
\hline Moderate & & $7(2)$ & & $6(2)$ & $0(0)$ & $6(2.7)$ & \\
\hline Poor & & $17(4.9)$ & & $15(5)$ & $4(5.2)$ & $11(5)$ & \\
\hline
\end{tabular}

$A R$, Aortic regurgitation; $B S A$, body surface area; $C V A$, cerebrovascular accident; $D M$, diabetes mellitus; $N Y H A$, New York Heart Association; $S D$, standard deviation. *Number of patients with data available.

28 patients, were not valve-related cardiac in 16 patients, were valve-related in 23 patients (sudden unexpected unexplained death in 15 , intracranial bleeding in 1 , endocarditis in 4, and structural valve deterioration in 3 [ 1 after reoperation and 2 due to heart failure]), and of unknown cause in 12 patients. The overall parametric estimates of survival at 1 year, 5 years, 10 years, and 15 years were $93 \%, 86 \%$, $78 \%$, and $65 \%$, respectively (Figures 1 and E1). Risk factors associated with early and late death are shown in Table 3.
During follow-up, 103 patients required a reoperation; of these operations, 81 were performed for structural valve deterioration, 18 were performed for nonstructural valve failure, and 4 were performed for allograft endocarditis. After taking the competing occurrence of death into account, the overall parametric estimates of freedom from reoperation at 1 year, 5 years, 10 years, and 15 years were $97 \%, 92 \%, 80 \%$, and $56 \%$, respectively (Figures 1 and E1). Risk factors associated with early and late reoperation are shown in Table 3. 
TABLE 2. Perioperative characteristics of patients used for clinical follow-up (total cohort) and echocardiographic follow-up (echocardiography cohort)

\begin{tabular}{|c|c|c|c|c|c|c|c|}
\hline \multirow[b]{2}{*}{ Characteristic } & \multicolumn{2}{|c|}{$\begin{array}{c}\text { Total cohort } \\
(\mathrm{n}=\mathbf{3 5 6})\end{array}$} & \multicolumn{2}{|c|}{$\begin{array}{c}\text { Echocardiography } \\
\text { cohort }(n=301)\end{array}$} & \multirow{2}{*}{$\begin{array}{c}\begin{array}{c}\text { Subcoronary } \\
(\mathrm{n}=77 / 301)\end{array} \\
P \text { value }\end{array}$} & \multirow{2}{*}{$\begin{array}{l}\text { Root replacement } \\
(n=224 / 301) \\
\text { No. }(\%) \text { or } \\
\text { mean } \pm \text { SD }\end{array}$} & \multirow{2}{*}{$\begin{array}{c}\begin{array}{c}\text { Subcoronary vs } \\
\text { root replacement }\end{array} \\
P \text { value }\end{array}$} \\
\hline & n $(\%) *$ & $\begin{array}{l}\text { No. }(\%) \text { or } \\
\text { mean } \pm \text { SD }\end{array}$ & n $(\%) *$ & $\begin{array}{l}\text { No. }(\%) \text { or } \\
\text { mean } \pm \text { SD }\end{array}$ & & & \\
\hline Female donor gender & $345(97)$ & $130(38)$ & $294(98)$ & $109(37)$ & $24(32)$ & $85(39)$ & .34 \\
\hline Allograft diameter & $353(99)$ & $22.7 \pm 2.05$ & $300(100)$ & $22.7 \pm 1.92$ & $23.3 \pm 2.13$ & $22.5 \pm 1.82$ & .007 \\
\hline \multicolumn{8}{|l|}{ Procedure } \\
\hline Perfusion time & $355(99)$ & $197 \pm 77.6$ & $300(100)$ & $194 \pm 76.8$ & $177 \pm 41.7$ & $200 \pm 85$ & .21 \\
\hline Crossclamp time & $355(99)$ & $141 \pm 57.8$ & $300(100)$ & $141 \pm 58.7$ & $134 \pm 31.7$ & $143 \pm 65.4$ & .77 \\
\hline Circulatory arrest & $353(99)$ & $3.55 \pm 14.5$ & $300(100)$ & $3.79 \pm 15.2$ & $0 \pm 0$ & $5.1 \pm 17.4$ & $<.001$ \\
\hline Type of allograft implanted & $355(100)$ & & $300(100)$ & & & & .31 \\
\hline Aortic & & 297 & & $298(99 \%)$ & $76(99)$ & $222(99)$ & \\
\hline Pulmonary & & 6 & & $2(1 \%)$ & $1(1)$ & $1(1)$ & \\
\hline Allograft preservation method & $356(100)$ & & $301(100)$ & & & & .1 \\
\hline Cryopreserved & & $349(98)$ & & $298(99)$ & $75(97.4)$ & $223(99.6)$ & \\
\hline Fresh & & $7(2)$ & & $3(1)$ & $2(2.6)$ & $1(0.4)$ & \\
\hline Concomitant procedures & & & 299 (99) & & & & $<.001$ \\
\hline CABG & 354 (99) & $34(9.6)$ & & $30(10)$ & $10(13)$ & $20(9)$ & \\
\hline Mitral valve surgery & 354 (99) & $25(7.1)$ & & $17(5.7)$ & $7(9.1)$ & $10(4.5)$ & \\
\hline Extended root surgery & $354(99)$ & $48(14)$ & & $44(15)$ & $0(0)$ & $44(20)$ & \\
\hline Other procedures & $354(99)$ & $65(18)$ & & $50(17)$ & $7(9.1)$ & $43(19)$ & \\
\hline Rhythm at discharge & $345(97)$ & & $300(100)$ & & & & .16 \\
\hline Sinus rhythm & & $305(88)$ & & $276(92)$ & $68(88)$ & $208(93)$ & \\
\hline Atrial fibrillation & & $11(3.2)$ & & $11(3.7)$ & $5(6.5)$ & $6(2.7)$ & \\
\hline Heart block & & $12(3.5)$ & & $10(3.3)$ & $2(2.6)$ & $8(3.6)$ & \\
\hline Other rhythm & & $6(1.7)$ & & $3(1)$ & $2(2.6)$ & $1(0.45)$ & \\
\hline \multicolumn{8}{|l|}{ Complications } \\
\hline Postoperative bleeding & 347 (97) & $46(13)$ & $301(100)$ & $36(12)$ & $11(14)$ & $25(11)$ & .47 \\
\hline Postoperative pacemaker & $346(97)$ & $16(4.6)$ & $301(100)$ & $9(3)$ & $2(2.6)$ & $7(3.1)$ & .81 \\
\hline
\end{tabular}

$C A B G$, Coronary artery bypass grafting; $S D$, standard deviation. *Number of patients with data available.

\section{Echocardiographic Follow-up}

Aortic regurgitation. A total of 1728 echocardiographic measurements of $\mathrm{AR}$ in 300 patients were available; 37

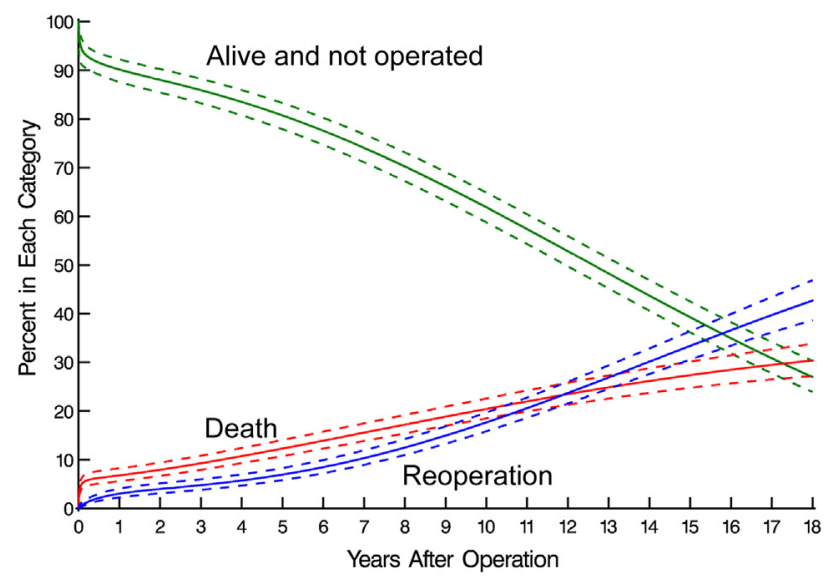

FIGURE 1. Competing risks of outcomes. Prevalence of death (red) and reoperation (blue) at each moment in time of patients in each of mutually exclusive categories in the overall group. Parametric estimates enclosed within $95 \%$ confidence limits show patient mortality (in red), reoperation (in blue), and patients being alive and not undergoing reoperation (green). patients had 1 or more echocardiographic measurements of AR beyond 15 years. Temporal trend analyses yielded only 1 phase. Figure 2 shows the temporal change in the percentages of patients in each AR grade over time. The percentage of patients in each grade of AR has changed significantly over time. Although the percentage of patients with AR grade 0 decreased sharply from $38 \%$ at 6 month to $20 \%$ by 15 years after the procedure and the percentage of patients with grade $1+$ remained the same at approximately $40 \%$ during the same time period, the percentage of patients with grade $2+$ increased sharply from $19 \%$ to $31 \%$. The percentage of patients with grade $3+/ 4+$ increased gradually from $3.6 \%$ to $10 \%$ during the same time period.

The subcoronary implantation group was associated with a higher postoperative AR grade than the root replacement group $(P=.0001)$ (Figure E2). The potential risk factors associated with AR grade over time are shown in Table 4. Younger age was associated with a higher grade of postoperative AR $(P=.0007)$, and the effect was significant in the subcoronary group (Figure E3). Furthermore, endocarditis seems to be associated with a lower likelihood of postoperative AR grade $(P=.0250)$. 
TABLE 3. Incremental risk factors for death and reoperation after aortic valve implantation

\begin{tabular}{lrcc}
\hline & Coefficient \pm SD & P value & $\begin{array}{c}\text { Reliability* } \\
(\%)\end{array}$ \\
\hline Death & & & \\
$\quad$ Early hazard phase & & & \\
$\quad$ Age $\ddagger$ & $1.85 \pm 0.48$ & .0001 & 76 \\
$\quad$ History of endocarditis & $1.58 \pm 0.60$ & .0092 & 63 \\
$\quad$ Renal disease & $2.82 \pm 0.60$ & $<.0001$ & 91 \\
Late hazard phase & & & \\
$\quad$ Age $\ddagger$ & $1.33 \pm 0.21$ & $<.0001$ & 100 \\
$\quad$ Renal disease & $0.48 \pm 0.26$ & .041 & 59 \\
Reoperation & & & \\
Early hazard phase & & & \\
$\quad$ Early date of surgery $\dagger$ & $-0.97 \pm 0.25$ & $<.0001$ & 55 \\
$\quad$ Renal disease & $2.21 \pm 0.65$ & .001 & 66 \\
Late hazard phase & & & \\
$\quad$ Age & & & \\
$\quad$ Aortic ascending & $0.05 \pm 0.01$ & $<.0001$ & 100 \\
$\quad$ aneurysm & & .001 & 66 \\
\hline
\end{tabular}

SD, Standard deviation. *Percentage of occurrence in 1000 bootstrapped models. $\nmid$ Log (time interval [date of surgery January 3, 1987]). ‡Exp[age/50], exponential transformation.

Aortic gradient. A total of 1609 echocardiographic measurements of aortic gradient in 292 patients were available; 34 patients had 1 or more echocardiographic measurements of aortic gradient beyond 15 years. Temporal trend analyses yielded only 1 phase. Aortic gradient increases from 9.4 $\mathrm{mm} \mathrm{Hg}$ at 6 months to $21.3 \mathrm{~mm} \mathrm{Hg}$ by 15 years after the procedure (Figure 3).

The subcoronary implantation group is associated with a higher aortic gradient than the root replacement group $(P=.0005)$. Younger age is associated with a higher aortic

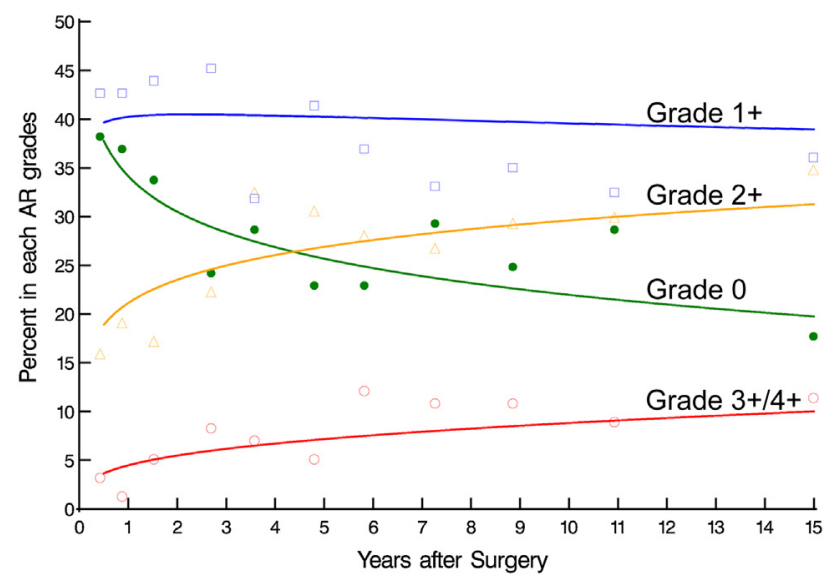

FIGURE 2. Temporal trend of AR after the procedure (grade $0=$ green, grade $1+=$ blue, grade $2+=$ orange, grade $3+/ 4+=$ red). Solid lines represent percentage of patients (mean effect) in each grade at various time points. Symbols represent crude estimates of grouped raw data without regard to repeated measures and are presented to verify the model fitting. $A R$, Aortic regurgitation. gradient $(P<.0001)$ (Figure E4). Male donor gender $(P=.0015)$ and concomitant mitral valve surgery $(P=.0011)$ were associated with higher aortic gradient during follow-up. The potential risk factors associated with aortic gradient over time are shown in Table 4.

Annulus diameter. A total of 1445 echocardiographic measurements of annulus diameter in 284 patients were available; 31 patients had 1 or more echocardiographic measurements of annulus diameter beyond 15 years. Temporal trend analyses yielded only 1 phase. Annulus diameter increased from $21.9 \mathrm{~mm}$ at 6 months to $22.4 \mathrm{~mm}$ by 15 years after the procedure. This increase was not statistically significant $(P=.5460)$ (Figure E5).

There is a procedure effect on the annulus diameter, and the root replacement technique is associated with a larger annulus diameter $(P<.0001)$ (Figure E6). Male donor gender $(P<.0047)$, male patient gender $(P<.0001)$, and higher allograft diameter $(P<.0001)$ were associated with larger annulus diameter during follow-up. The potential risk factors associated with annulus diameter over time are shown in Table 4.

Left ventricular outflow tract diameter. A total of 1463 echocardiographic measurements of LVOT diameter in 286 patients were available; 32 patients had 1 or more echocardiographic measurements of LVOT diameter beyond 15 years. Temporal trend analyses yielded only 1 phase. No significant change in the LVOT diameter was observed $(P=.6582)$ with a diameter of approximately $21.8 \mathrm{~mm}$ at 6 months and $22.0 \mathrm{~mm}$ at 15 years after the procedure (Figure E7).

Male donor gender $(P<.0001)$, aortic annulus aneurysm $(P=.0011)$, and tricuspid aortic valve $(P=.0011)$ were associated with larger LVOT diameter during follow-up. Larger allograft diameter was associated with larger LVOT diameter during follow-up. The potential risk factors associated with LVOT diameter over time are shown in Table 4.

Aortic diameter. A total of 1603 echocardiographic measurements of aortic diameter in 294 patients were available; 34 patients had 1 or more echocardiographic measurements of aortic diameter beyond 15 years. Temporal trend analyses yielded only 1 phase. Aortic diameter decreased slightly from $34.3 \mathrm{~mm}$ at 6 months to $32.7 \mathrm{~mm}$ at 12 years after the procedure. Although the decrease is statistically significant $(P<.0001)$, it may not be clinically significant (Figure E8).

Male donor gender $(P<.0001)$, calcified aortic annulus $(P=.0061)$, preoperative AR $(P<.0001)$, male patient gender $(P<.0001)$, and elective surgery $(P=.0106)$ were associated with larger aortic diameter during followup. Concomitant mitral valve surgery $(P=.0496)$ was associated with smaller aortic diameter during follow-up. The potential risk factors associated with aortic diameter over time are shown in Table 4. 
TABLE 4. Preoperative risk factors associated with postoperative longitudinal echocardiographic measurement (results from the multivariate analyses)

\begin{tabular}{|c|c|c|c|c|}
\hline Echocardiographic measurement & Factor & Estimate $\pm S E$ & $\boldsymbol{P}$ & Reliability* (\%) \\
\hline \multirow[t]{3}{*}{ AR } & Younger age $\dagger$ & $-1.44 \pm 0.42$ & .0007 & 90.0 \\
\hline & Subcoronary AVR (vs root replacement) & $2.48 \pm 0.33$ & $<.0001$ & 100 \\
\hline & Endocarditis & $-0.70 \pm 0.31$ & .0250 & 73.2 \\
\hline \multirow[t]{4}{*}{ Aortic gradient } & Male donor & $0.17 \pm 0.05$ & .0015 & 98.0 \\
\hline & Subcoronary AVR (vs root replacement) & $0.21 \pm 0.06$ & .0005 & 100 \\
\hline & Younger age & $-0.01 \pm 0.00$ & $<.0001$ & 93.5 \\
\hline & Concomitant mitral valve surgery & $0.25 \pm 0.12$ & .0445 & 91.5 \\
\hline \multirow[t]{4}{*}{ Annulus diameter } & Larger allograft diameter & $0.03 \pm 0.01$ & $<.0001$ & 96.7 \\
\hline & Male donor & $0.05 \pm 0.02$ & .0047 & 52.8 \\
\hline & Male recipient & $0.09 \pm 0.02$ & $<.0001$ & 58.3 \\
\hline & Root replacement AVR (vs subcoronary) & $0.07 \pm 0.02$ & $<.0001$ & 65.2 \\
\hline \multirow[t]{4}{*}{ LVOT diameter } & Male gender & $0.10 \pm 0.02$ & $<.0001$ & 84.2 \\
\hline & Aortic annulus aneurysm & $0.08 \pm 0.03$ & .0011 & 82.1 \\
\hline & Tricuspid vs bicuspid aortic valve & $0.08 \pm 0.03$ & .0011 & 67.3 \\
\hline & Smaller allograft diameter & $-0.04 \pm 0.02$ & .0123 & 59.4 \\
\hline \multirow[t]{6}{*}{ Aortic diameter } & Male donor gender & $0.07 \pm 0.01$ & $<.0001$ & 99.3 \\
\hline & Calcified aortic annulus & $0.04 \pm 0.02$ & .0061 & 94.6 \\
\hline & Preoperative AR & $0.05 \pm 0.01$ & $<.0001$ & 78.8 \\
\hline & Male patient gender & $0.09 \pm 0.01$ & $<.0001$ & 65.7 \\
\hline & Elective surgery & $0.03 \pm 0.01$ & .0106 & 99.3 \\
\hline & Concomitant mitral valve surgery & $-0.05 \pm 0.03$ & .0496 & 61.3 \\
\hline
\end{tabular}

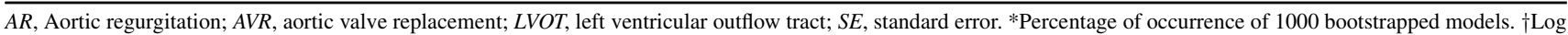
[age], logarithmic transformation.

\section{DISCUSSION}

This study describes echocardiographic allograft valve function over time in a cohort of patients who were followed prospectively after allograft aortic valve or root replacement, illustrating the use of longitudinal data analysis for the assessment of valve function over time.

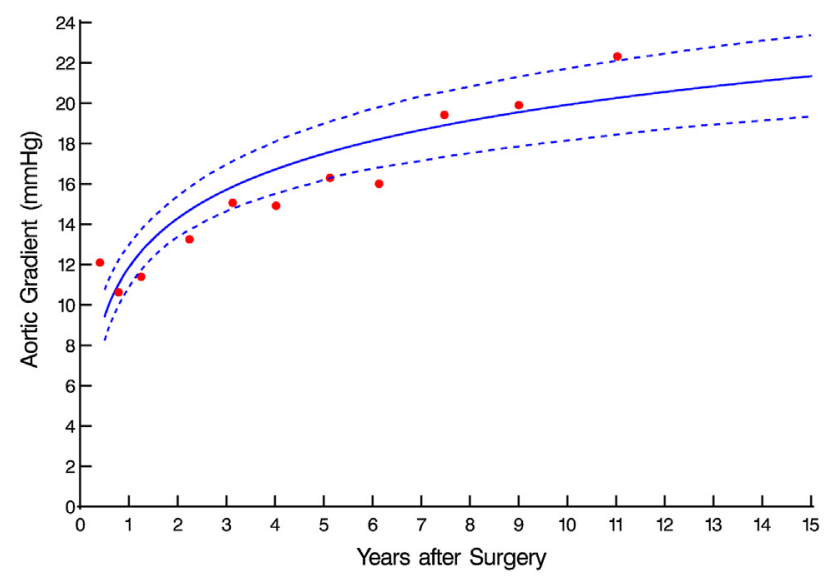

FIGURE 3. Solid lines are parametric estimates of mean aortic gradient from nonlinear longitudinal mixed model and are enclosed within dashed $95 \%$ bootstrap percentile confidence bands, equivalent to 2 standard deviations. Symbols represent crude estimates of grouped raw data without regard to repeated measures and are presented to verify the model fitting.

\section{Clinical Outcomes}

In our patient population, patient survival was $68 \%$ after 15 years of follow-up. Freedom from reoperation was $56 \%$ after 15 years of follow-up. These results are comparable to other series that report survival and freedom from reoperation after allograft aortic valve and root replacement. ${ }^{15-19}$

\section{Echocardiographic Outcomes}

Among patients who underwent allograft aortic valve or root replacement, $41 \%$ had $2+$ or higher AR after 15 years of follow-up. In patients in whom the complete aortic root was implanted instead of the aortic valve in the subcoronary position, the risk of higher AR grade was considerably lower during follow-up. Furthermore, we observed higher AR grades more often during follow-up in younger patients. Although it has been shown that younger patients are at higher risk of aortic allograft degeneration, ${ }^{20}$ the results of our longitudinal echocardiographic study show that younger patients are especially at risk for valve degeneration when the subcoronary implantation technique is used to implant the allograft.

The aortic gradient increased during follow-up from 9.4 $\mathrm{mm} \mathrm{Hg}$ at 6 months to $21.3 \mathrm{~mm} \mathrm{Hg}$ at 15 years. Comparable to AR, the severity of aortic gradient during follow-up was primarily influenced by younger patient age and the use of the subcoronary implantation technique. Furthermore, male donor gender was found to be significantly correlated with higher aortic gradient during follow-up, which confirms the 
results of previous studies in which it has been shown that immunologic reaction might be (partly) responsible for valve failure. ${ }^{21}$ We have not observed major changes in the annulus diameter, LVOT diameter, and aortic diameter during follow-up.

The results of our longitudinal data analyses of echocardiographic valve function over time indicate that both younger patient age and subcoronary implantation technique are important risk factors of allograft degeneration. This is in accordance with previous studies that investigated the clinical outcomes of patients with aortic allograft. $^{20,22-24}$

\section{Methodology}

The described methodology for the analyses of echocardiographic data was applied in the present study for several reasons.

Longitudinal analyses versus time-to-event analyses. The assessment of allograft valve performance (and other valve substitutes) is complicated by several factors. First, valves are implanted in patients who have a limited survival. This creates a situation in which the risk of patient death competes with valve durability. Second, valve failure is a continuous process, not a hard end point. Therefore, timeto-event analysis is inappropriate when assessing echocardiographic valve function, because it considers time of follow-up as a continuous variable, whereas echocardiographic data are usually available within a certain time frame and often incomplete in 1 or more time frames. In addition, those data consider valve dysfunction as an irreversible end point, whereas severity of valve dysfunction (eg, AR) is often variable over time. Third, the means by which echocardiographic follow-up is obtained may influence the results: Opportunistic versus standardized follow-up, experience of the observer, and intervals between measurements all may cause bias. Finally, allograft dysfunction may present in different ways, through regurgitation, stenosis, or a combination, further complicating valve performance analysis. The challenge in analyzing longitudinal data is estimating the average pattern of outcome over time and its variability in the group of patients. In addition, this average must take several sampling characteristics into account (eg, censoring by death, unequal number of observations per patient, and different follow-up intervals between observations).

In the present study, nonlinear longitudinal analysis techniques were used to model the trend of various echocardiographic measurements over time after the procedure. This enabled us in turn to visualize the temporal trend of, for example, each AR grade over time during follow-up. Clinicians can use such methods/graphs to determine how AR on average develops over time after aortic allograft implantation. From a statistical perspective, the methods used are superior and more informative compared with the methods where repeated outcomes are dichotomized and analyzed with actuarial methods as if they were events, such as freedom from grade $1+$ or $3+$ AR after aortic valve surgery. ${ }^{4,5}$ Assessing the trend of outcomes of interest and identifying factors that influence these outcomes over time can be of particular importance because they can help the clinicians understand how a certain process changes over time and thus can contribute to better patient management (eg, by determining which patients should be monitored more closely by their physicians and at which time interval).

Although the use of time-to-event methods is less timeand effort-consuming, these methods have major limitations that may result in loss of information and wrong statistical inferences that can lead to inadequate conclusions, depending on the type of research question investigated. Therefore, researchers should be encouraged in taking into account the important characteristics of longitudinally collected data when choosing the method of data analysis.

Methods applied in the present study versus other typical longitudinal analyses methods. Several longitudinal analyses methods exist. Both linear and nonlinear structures can be used to analyze longitudinal data. In linear methods, the degree of the outcome (y) is determined by the degree of the input $(\mathrm{x})$, which can be written as a $\mathrm{y}=\mathrm{ax}+\mathrm{b}$ equation. An important characteristic of linear methods is proportionality because there is a straight-line relationship between the input value and the outcome. Therefore, the behavior of linear methods can be fully predicted. However, the cardiovascular system is a complex mechanical, chemical, and hemodynamic system in which the processes are often related via a variety of mechanisms. Therefore, these processes are often nonlinearly structured. ${ }^{25-27}$ Because the principle of proportionality may not be valid, using linear methods may mean simplification of the real process and therefore inaccurate results and inferences. For example, the analyses of our study show that aortic gradient is nonlinearly shaped. During follow-up, the increase in aortic gradient mainly occurred in the first 5 years after the surgery. If we had modeled the aortic gradient as a linear process, we would not be able to see the difference between how the aortic gradient increased before and after this 5 -year period. We emphasize that not the data but the model determines the shape of the relationship between the input and the outcome. However, further validation is necessary to confirm whether the nonlinear pattern is indeed the better description of aortic gradient measurements.

The statistical methods that we applied are able to simultaneously model the risk factors for each time phase, whereas in case when one has to use the usual longitudinal methods to identify time-dependent risk factors, several transformations of time along with their interaction effects 
are needed in the equation. In the latter scenario, it would be difficult for the model to handle 40 or 50 covariates, and the combination of them with different transformations of time and the interpretation of such model would be difficult. The statistical technique that has been illustrated in this study is able to explicitly model the nonlinear trend and divides it in different overlapping time phases, which in turn enable us to simultaneously identify risk factors that are of particular importance shortly after the procedure and those that are of particular importance in the long-term. The approach of longitudinal data analyses that is used in the present study is also proposed by the 2008 guidelines for reporting mortality and morbidity after cardiac valvular interventions. ${ }^{6}$

\section{CONCLUSIONS}

Both AR and stenosis increase over time after allograft aortic valve or root replacement and are the most important cause for allograft failure. Younger patient age and use of the subcoronary implantation technique are associated with increased regurgitation and stenosis. The analysis of allograft valve function is complex and requires advanced longitudinal models for adequate statistical analysis.

\section{References}

1. Ross DN. Homograft replacement of the aortic valve. Lancet. 1962;2:487.

2. Smedira NG, Blackstone EH, Roselli EE, Laffey CC, Cosgrove DM. Are allografts the biologic valve of choice for aortic valve replacement in nonelderly patients? Comparison of explantation for structural valve deterioration of allograft and pericardial prostheses. J Thorac Cardiovasc Surg. 2006;131: 558-64.e554.

3. Takkenberg JJ, Klieverik LM, Bekkers JA, Kappetein AP, Roos JW, Eijkemans MJ, et al. Allografts for aortic valve or root replacement: insights from an 18-year single-center prospective follow-up study. Eur J Cardiothorac Surg. 2007;31:851-9.

4. Murashita T, Kubota T, Kamikubo Y, Shiiya N, Yasuda K. Long-term results of aortic valve regurgitation after repair of ruptured sinus of Valsalva aneurysm. Ann Thorac Surg. 2002;73:1466-71.

5. Losay J, Touchot A, Capderou A, Piot JD, Belli E, Planche C, et al. Aortic valve regurgitation after arterial switch operation for transposition of the great arteries: incidence, risk factors, and outcome. J Am Coll Cardiol. 2006;47:2057-62.

6. Akins CW, Miller DC, Turina MI, Kouchoukos NT, Blackstone EH, Grunkemeier GL, et al. Guidelines for reporting mortality and morbidity after cardiac valve interventions. J Thorac Cardiovasc Surg. 2008;135:732-8.

7. Ross D. Technique of aortic valve replacement with a homograft: orthotopic replacement. Ann Thorac Surg. 1991;52:154-6.

8. Willems TP, Takkenberg JJ, Steyerberg EW, Kleyburg-Linkers VE, Roelandt JR, Bos E, et al. Human tissue valves in aortic position: determinants of reoperation and valve regurgitation. Circulation. 2001;103:1515-21.
9. Blackstone EH, Naftel DC, Turner ME Jr. The decomposition of time-varying hazard into phases, each incorporating a separate stream of concomitant information. J Am Stat Assoc. 1986;81:615-24.

10. Blackstone EH, Rajeswaran J. A non-linear cumulative logit mixed model with time varying phases and coefficients. Conference proceedings, XXIII International Biometric Conference, Montreal, Canada, 2006.

11. Gillinov AM, McCarthy PM, Blackstone EH, Rajeswaran J, Pettersson G, Sabik JF, et al. Surgical ablation of atrial fibrillation with bipolar radiofrequency as the primary modality. J Thorac Cardiovasc Surg. 2005;129:1322-9.

12. Blackstone EH. Breaking down barriers: helpful breakthrough statistical methods you need to understand better. J Thorac Cardiovasc Surg. 2001;122: 430-9.

13. Diggle PJ, Heagerty PJ, Liang KY, Zeger SL. Analysis of Longitudinal Data. 2nd ed. New York: Oxford University Press; 2002.

14. Mason DP, Rajeswaran J, Murthy SC, McNeill AM, Budev MM, Mehta AC, et al. Spirometry after transplantation: how much better are two lungs than one? Ann Thorac Surg. 2008;85:1193-201, 1201.e1191-2.

15. Dagenais F, Cartier P, Voisine P, Desaulniers D, Perron J, Baillot R, et al. Which biologic valve should we select for the 45- to 65-year-old age group requiring aortic valve replacement? J Thorac Cardiovasc Surg. 2005;129: 1041-9.

16. Knott-Craig CJ, Elkins RC, Santangelo KL, McCue C, Lane MM. Aortic valve replacement: Comparison of late survival between autografts and homografts. Ann Thorac Surg. 2000;69:1327-32.

17. Lund O, Chandrasekaran V, Grocott-Mason R, Elwidaa H, Mazhar R, Khaghani A, et al. Primary aortic valve replacement with allografts over twenty-five years: valve-related and procedure-related determinants of outcome. J Thorac Cardiovasc Surg. 1999;117:77-91.

18. O'Brien MF, Harrocks S, Stafford EG, Gardner MA, Pohlner PG, Tesar PJ, et al. The homograft aortic valve: a 29-year, 99.3\% follow up of 1,022 valve replacements. J Heart Valve Dis. 2001;10:334-45.

19. Dossche KM, de la Riviere AB, Morshuis WJ, Schepens MA, Defauw JJ, Ernst SM. Cryopreserved aortic allografts for aortic root reconstruction: a single institution's experience. Ann Thorac Surg. 1999;67:1617-22.

20. Yacoub M, Rasmi NR, Sundt TM, Lund O, Boyland E, Radley-Smith R, et al. Fourteen-year experience with homovital homografts for aortic valve replacement. J Thorac Cardiovasc Surg. 1995;110:186-94.

21. Grunkemeier GL, Bodnar E. Comparison of structural valve failure among different 'models' of homograft valves. J Heart Valve Dis. 1994;3:556-60.

22. O'Brien MF, Stafford EG, Gardner MA, Pohlner PG, Tesar PJ, Cochrane AD, et al. Allograft aortic valve replacement: long-term follow-up. Ann Thorac Surg. 1995;60:S65-70.

23. Rubay JE, Raphael D, Sluysmans T, Vanoverschelde JL, Robert A, Schoevaerdts JC, et al. Aortic valve replacement with allograft/autograft: subcoronary versus intraluminal cylinder or root. Ann Thorac Surg. 1995;60:S78-82.

24. Willems TP, van Herwerden LA, Taams MA, Kleyburg-Linker VE, Roelandt JR, Bos E. Aortic allograft implantation techniques: pathomorphology and regurgitant jet patterns by Doppler echocardiographic studies. Ann Thorac Surg. 1998; 66:412-6.

25. Elbert T, Ray WJ, Kowalik ZJ, Skinner JE, Graf KE, Birbaumer N. Chaos and physiology: deterministic chaos in excitable cell assemblies. Physiol Rev. 1994; 74:1-47.

26. Sugihara G, Allan W, Sobel D, Allan KD. Nonlinear control of heart rate variability in human infants. Proc Natl Acad Sci U S A. 1996;93:2608-13.

27. Scher AM, Young AC. Nonlinearity in the control of blood pressure and heart rate. Ann N Y Acad Sci. 1969;156:722-30. 


\section{ONLINE METHODS}

\section{Clinical Follow-up}

All patients who receive a human tissue valve at the Erasmus University Medical Center are enrolled in an ongoing prospective follow-up study. They are followed systematically and actively through direct annual patient contact by telephone. Clinical follow-up was based on the data obtained from the total cohort of 356 aortic valve or root replacements that were performed during the study period.

Valve-related complications and their consequences were defined according to the 2008 guidelines for reporting morbidity and mortality after cardiac valvular operations ${ }^{\mathrm{E} 1}$ after confirmation of the event by the patient's treating physician. The database was frozen on September 30, 2010. Clinical follow-up was $95 \%$ complete (the ratio of total observed person time to potential person time of follow-up to the closing date of the study). ${ }^{\mathrm{E} 2}$ The mean clinical follow-up duration was 10.8 years (median, 10.8 years; range, 0-23.9 years), with a total follow-up of 3842 patient years.

\section{Echocardiographic Follow-up}

Of the 356 aortic valve or root replacements that were performed during the study period, 301 hospital survivors had 1 or more standardized echocardiographic examinations. The analyses of echocardiographic valve function over time were based on these 301 patients. Preoperative characteristics of these patients in the "echocardiography cohort" are shown in Table 1. A total of 1765 echocardiographic records were available for 301 patients. The mean echocardiographic follow-up was 5.6 years (median, 4.9 years; range, 1 week to 17 years) with $5 \%$ of the records collected after 15 years.

Postoperative transthoracic echocardiographic records were used to assess the hemodynamic stability of the prosthesis. The severity of aortic stenosis (millimeters of mercury) and AR were estimated according the guidelines. ${ }^{\mathrm{E} 3, \mathrm{E} 4} \mathrm{AR}$ was graded as 0 for no regurgitation, $1+$ for mild, $2+$ for moderate, $3+$ for moderately severe, and $4+$ for severe. Because of low frequency in grade $4+$, this grade was collapsed together with $3+$ and is treated as 1 category. Also, annulus diameter (millimeters), LVOT diameter (millimeters), and aortic diameter at the sinotubular junction (millimeters) were recorded with the "leading-edge to leading-edge" method. ${ }^{\mathrm{E} 5}$ At least 1 echocardiographic follow-up was obtained in $95 \%$ of eligible patients $(301 / 318 ; 318=352$ minus 5 patients who are still aged $<16$ years minus 25 patients who died in hospital or within the first 6 postoperative months minus 4 patients who had not yet reached the 6-month postoperative point in time). Reasons for not participating in the remaining $5 \%$ of eligible patients were emigration, refusal, and bad quality of echocardiography measurements (usually due to obesity).

The echocardiographic examinations were initially performed with different echocardiographic equipment. Since January 1993, all examinations are performed by 2 experienced technicians.

\section{Statistical Analyses}

Competing outcomes. The earliest occurrence after aortic allograft surgery of one of the mutually exclusive outcomes (assumed absorbing states) was identified: (1) reoperation or (2) death before reoperation. The common interval of the analysis was the interval between the date of reoperation and the earliest occurrence of one of these outcomes or the duration to last follow-up date of being alive without any reoperation. Freedom from each event was then estimated by the nonparametric product limit method. ${ }^{\mathrm{E} 6}$

Variances of the estimates were based on the Greenwood formula. ${ }^{\mathrm{E} 6}$ The instantaneous risk (hazard function) for each competing event was estimated by a parametric method. ${ }^{\mathrm{E}}$ Consequences of the independent transition rates (hazard functions) from the category "alive, at risk" into the event categories were calculated by integrating the parametric equations. ${ }^{\mathrm{E} 8}$

Variable selection and risk factor analyses. Baseline characteristics (Table 1) and perioperative characteristics (Table 2) were screened for association with death, reoperation, postoperative AR, aortic gradient, annulus diameter, LVOT diameter, and aortic diameter. In addition, year of surgery was included in the model as a potential risk factor.

Variable selection, with a $P$ value criterion for retention of variables in the model of .05 , used bootstrap bagging (bootstrap aggregation). ${ }^{\mathrm{E} 9, \mathrm{E} 10}$ This was a 4-step process. First, a patient was randomly selected from the original data set to begin a new data set. The original data set continued to be sampled until the new data set was $100 \%$ the size of the original. Second, risk factors were identified using automated forward stepwise selection. Third, results of the variable selection were stored. These 3 steps were repeated 1000 times. Finally, the frequency of occurrence of variables related to group membership was ascertained and indicated the reliability of each variable (aggregation step). All variables with bootstrap reliability of $50 \%$ or greater were retained in the guided analysis. Because of the limited capability of PROC NLMIXED to explore multivariable relations, we initially screened the variables using ordinary multivariable linear regression (PROC REG SAS; SAS Institute Inc, Cary, NC) and the assumption of independence of observations with liberal entry criteria (.2) and stay criteria (.12). This analysis was performed simply to identify possible candidates for our repeated measurements model. These candidates and their transformations, if any, were entered at once into our model and then eliminated one by one until all variables remaining had a $P$ value of .05 or less. Parametric estimates of continuous postoperative echocardiography measurements are accompanied by asymmetric $95 \%$ confidence limits, comparable to \pm 2 standard errors, obtained by a bootstrap percentile method. ${ }^{\text {E11 }}$

\section{E-References}

E1. Akins CW, Miller DC, Turina MI, Kouchoukos NT, Blackstone EH, Grunkemeier GL, et al. Guidelines for reporting mortality and morbidity after cardiac valve interventions. J Thorac Cardiovasc Surg. 2008;135:732-8.

E2. Clark TG, Altman DG, De Stavola BL. Quantification of the completeness of follow-up. Lancet. 2002;359:1309-10.

E3. Baumgartner H, Hung J, Bermejo J, Chambers JB, Evangelista A, Griffin BP, et al. Echocardiographic assessment of valve stenosis: EAE/ASE recommendations for clinical practice. J Am Soc Echocardiogr. 2009;22:1-23; quiz 101-2.

E4. Lancellotti P, Tribouilloy C, Hagendorff A, Moura L, Popescu BA, Agricola E, et al. European Association of Echocardiography recommendations for the assessment of valvular regurgitation. Part 1: Aortic and pulmonary regurgitation (native valve disease). Eur J Echocardiogr. 2010;11:223-44.

E5. Lang RM, Bierig M, Devereux RB, Flachskampf FA, Foster E, Pellikka PA, et al. Recommendations for chamber quantification: a report from the American Society of Echocardiography's Guidelines and Standards Committee and the Chamber Quantification Writing Group, developed in conjunction with the European Association of Echocardiography, a branch of the European Society of Cardiology. J Am Soc Echocardiogr. 2005;18:1440-63.

E6. Andersen PK, Borgan O, Gill RD, Keiding N. Chapter 4. Nonparametric estimation. In: Statistical Models Based on Counting Processes. New York Springer-Verlag; 1993:176-331.

E7. Blackstone EH, Naftel DC, Turner ME Jr. The decomposition of time-varying hazard into phases, each incorporating a separate stream of concomitant information. J Am Stat Assn. 1986;81:615-24.

E8. Blackstone EH, Lytle BW. Competing risks after coronary bypass surgery: the influence of death on reintervention. J Thorac Cardiovasc Surg. 2000;119:1221-30.

E9. Breiman L. Bagging predictors. Machine Learning. 1996;24:123-40.

E10. Blackstone EH. Breaking down barriers: helpful breakthrough statistical methods you need to understand better. J Thorac Cardiovasc Surg. 2001;122:430-9.

E11. Efron B, Tibshirani RJ. An Introduction to the Bootstrap. New York: Chapman and Hall/CRC; 1998. 


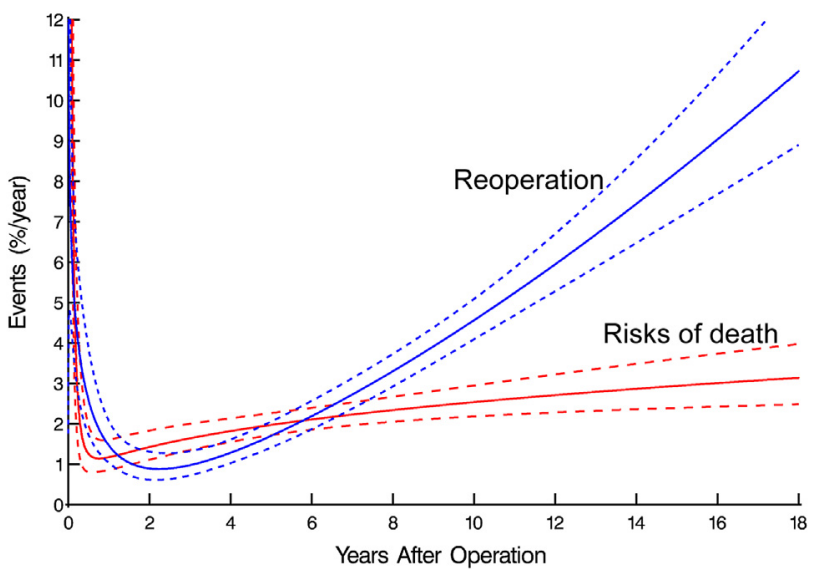

FIGURE E1. Instantaneous risks of death (red) and reoperation (blue) (hazard function). Solid lines are parametric estimates enclosed within $95 \%$ confidence limits.

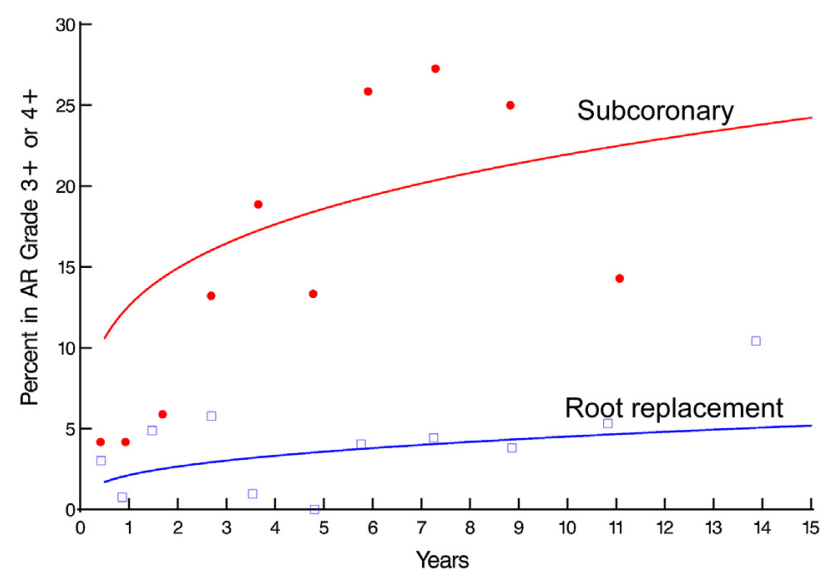

FIGURE E2. Predicted percentages of patients in AR grade $3+/ 4+$ stratified by operative technique (subcoronary $=r e d$; root replacement $=$ blue ). Symbols represent crude estimates of grouped raw data without regard to repeated measures and are presented to verify the model fitting. AR, Aortic regurgitation.

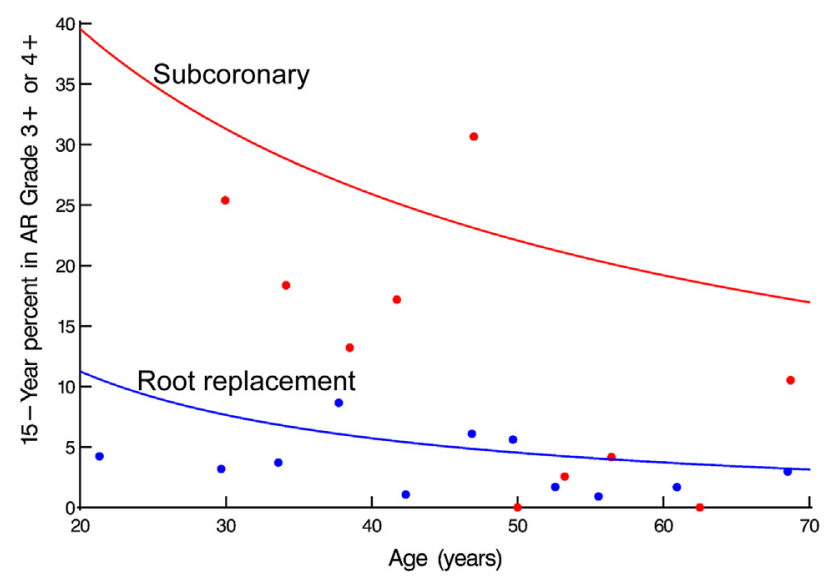

FIGURE E3. Fifteen-year predicted percentages of patients in AR grade $3+/ 4+$ by age, stratified by operative technique (subcoronary $=$ red; root replacement $=$ blue). Symbols represent crude estimates of grouped raw data without regard to repeated measures and are presented to verify the model fitting. $A R$, Aortic regurgitation.

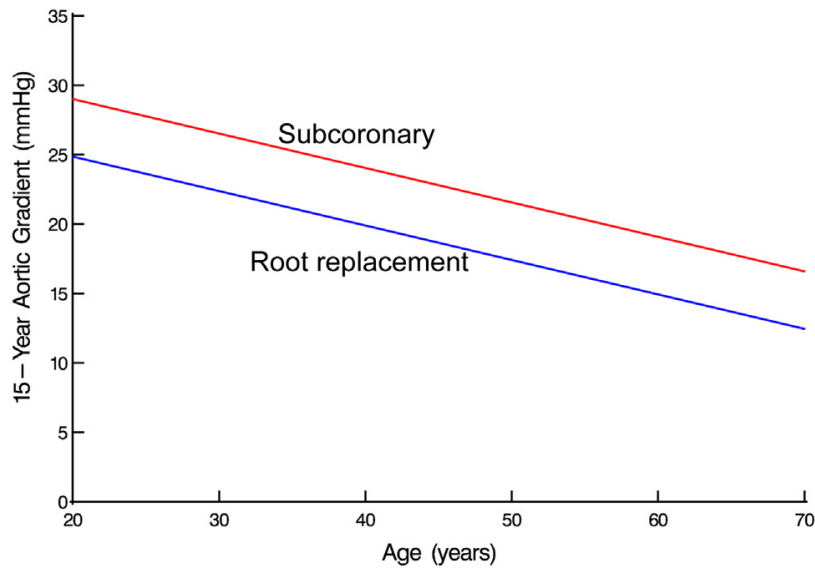

FIGURE E4. Fifteen-year predicted mean aortic gradient by age, stratified by operative techniques (subcoronary $=$ red; root replacement $=$ blue).

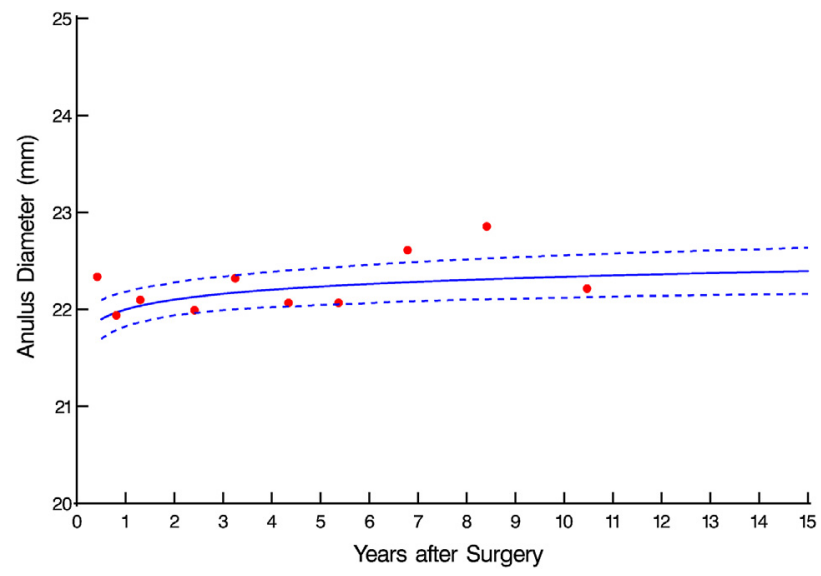

FIGURE E5. Solid lines are parametric estimates of mean annulus diameter from nonlinear longitudinal mixed model and are enclosed within dashed $95 \%$ bootstrap percentile confidence bands, equivalent to 2 standard deviations. Symbols represent crude estimates of grouped raw data without regard to repeated measures and are presented to verify the model fitting.

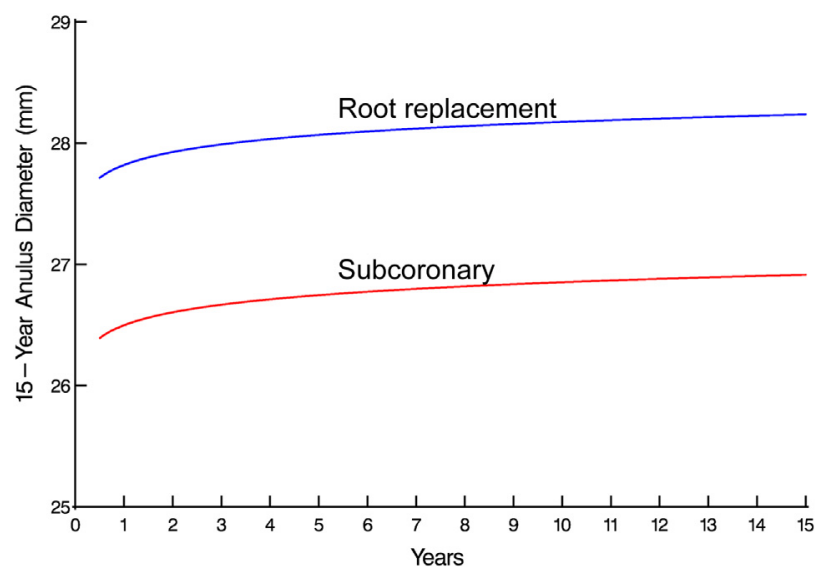

FIGURE E6. Fifteen-year predicted mean of annulus diameter, stratified by operative technique (subcoronary $=$ red; root replacement $=$ blue ). 


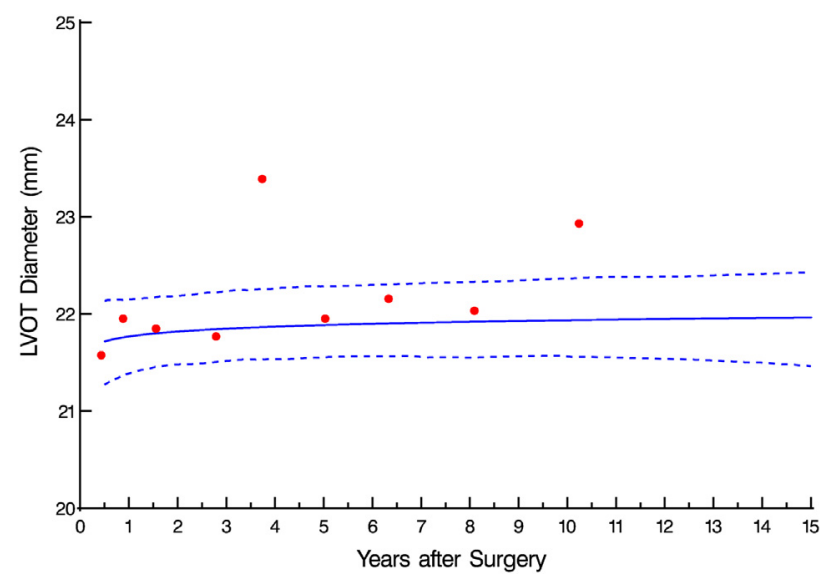

FIGURE E7. Solid lines are parametric estimates of mean LVOT diameter from nonlinear longitudinal mixed model and are enclosed within dashed $95 \%$ bootstrap percentile confidence bands, equivalent to 2 standard deviations. Symbols represent crude estimates of grouped raw data without regard to repeated measures and are presented to verify the model fitting. $L V O T$, Left ventricular outflow tract.

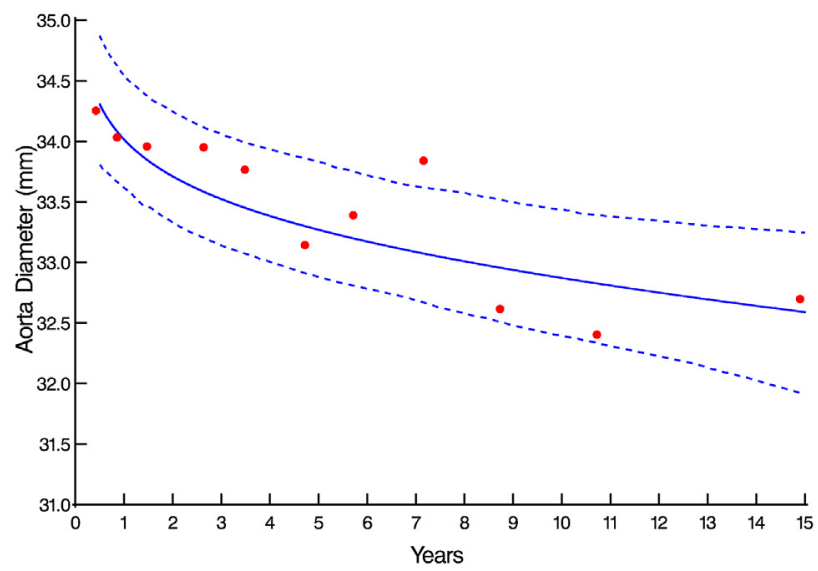

FIGURE E8. Solid lines are parametric estimates of mean aortic diameter from nonlinear longitudinal mixed model and are enclosed within dashed $95 \%$ bootstrap percentile confidence bands, equivalent to 2 standard deviations. Symbols represent crude estimates of grouped raw data without regard to repeated measures and are presented to verify the model fitting. 